\title{
Auge inmobiliario y valorización diferencial del suelo urbano en la ciudad de Tandil (Argentina), en el período postconvertibilidad*
}

\section{Real estate boom and differential valuation of urban land in the city of Tandil (Argentina), in the period of posconvertibility}

\footnotetext{
Alejandro Migueltorena

Doctor en Geografía. Becario Posdoctoral en Temas Estratégicos, CONICET. Centro de Investigaciones Geográficas e Instituto de Geografía, Historia y Ciencias Sociales. Universidad Nacional del Centro de la Provincia de Buenos Aires. Consejo Nacional de Investigaciones Científicas y Técnicas. CIG-IGEHCS (UNCPBA/CONICET). Pinto 399, (7000) Tandil, Buenos Aires, Argentina, ale_gardey@hotmail.com
}

Recibido: 5 de agosto 2019 || Aprobado: 6 de marzo 2020

Resumen

El siguiente trabajo se propone analizar los procesos sociales que generaron un importante dinamismo de la actividad inmobiliaria y los cambios residenciales que ocurrieron a escala intra-urbana en la ciudad de Tandil, en los años que siguieron a la crisis que finalizó con el modelo económico de la convertibilidad. Para contribuir a este objetivo también se realizó un estudio de la evolución de los precios del suelo urbano a lo largo de este período y se consideraron las modificaciones registradas en el régimen de tenencia de las viviendas. Para ello se adoptó una metodología en la cual se combinaron datos provenientes de fuentes de información secundaria, entrevistas realizadas a informantes clave (martilleros y empresarios constructores de la ciudad) y un relevamiento de precios del suelo urbano confeccionado mediante la búsqueda de avisos clasificados en un periódico local.

Palabras clave: Auge inmobiliario; Suelo urbano; Vivienda; Tandil

Abstract

The following paper aims to analyze the causes that led to an important dynamism of the real estate activity and the residential changes that were generated at intra-urban scale in the city of Tandil, in the years following the crisis that ended with the economic model of convertibility. In order to contribute to this objective, a study was also carried out on the evolution of urban land prices over this period and the changes in housing tenure were considered. To this end, a methodology was adopted that combined data from secondary information sources, interviews with key informants (hammermakers and construction entrepreneurs in the city) and a price survey of the urban land made by searching for ads classified in a local newspaper.

Key words: Real estate boom; Urban land; Housing; Tandil

\footnotetext{
* En Argentina, durante la década de 1990 y hasta la crisis económica, política y social del año 2001, prevaleció un modelo económico de corte neoliberal, que tuvo entre sus principales características la implementación de la paridad cambiaria entre el peso argentino y el dólar estadounidense, aplicado mediante la "Ley de convertibilidad del austral” N²3.928, en el año 1991. Dicha Ley fue derogada el 6 de enero de 2002, marcando el fin de la paridad cambiaria. A partir de ese entonces, comenzó un proceso que paulatinamente iría configurando las bases de un modelo económico que se apartaría en, algunos aspectos, de los dogmas establecidos por el Consenso de Washington.
}

Cita sugerida: Migueltorena, A. (2020). Auge inmobiliario y valorización diferencial del suelo urbano en la ciudad de Tandil (Argentina), en el período postconvertibilidad. Estudios Socioterritoriales. Revista de Geografía, (27), 044. DOI: https://doi.org/10.37838/unicen/est. 27-044 


\section{INTRODUCCIÓN}

A partir de los primeros años del siglo XXI se generaron una serie de condiciones que posibilitaron un importante crecimiento de la actividad inmobiliaria y de la industria de la construcción en la ciudad de Tandil. Dicho auge no resultó ajeno a lo que ocurrió a nivel nacional, debido a que en todos los espacios urbanos del país se registró este mismo fenómeno, especialmente en los primeros años, como consecuencia de la recuperación económica y de la implementación de políticas destinadas a la inversión pública. No obstante, también se originaron procesos especulativos que incrementaron exponencialmente los valores del suelo urbano y alejaron a una buena proporción de la masa trabajadora y explotada ${ }^{1}$ de la posibilidad de acceder a una vivienda propia. Esta situación revistió algunas particularidades en Tandil, relacionadas con su carácter de ciudad intermedia y con ciertas singularidades que presenta su estructura económica.

Este trabajo de investigación se propone identificar cuáles fueron los procesos (locales y nacionales) que generaron un importante dinamismo de la actividad inmobiliaria y los cambios residenciales que ocurrieron a escala intra-urbana en la ciudad de Tandil, en los años que siguieron a la crisis que finalizó con el modelo económico de la convertibilidad. También se realizó un estudio de la evolución de los precios del suelo urbano a lo largo de este período y se consideraron las modificaciones registradas en el régimen de tenencia de las viviendas.

Para ello se adoptó una metodología en la cual se combinaron datos provenientes de fuentes de información secundaria, entrevistas realizadas a informantes clave (martilleros y empresarios constructores de la ciudad) y un relevamiento de precios del suelo urbano confeccionado me-

\footnotetext{
1 Se recurre a la conceptualización realizada por Iñigo Carreras, Podestá y Fernández (1996, p. 4) quienes entienden que la masa trabajadora y explotada está "formada por el conjunto de los que, sean o no propietarios de sus condiciones materiales de existencia, es decir sean proletarios o pequeños propietarios, producen su vida por su propio trabajo y son explotados o expoliados por diversos mecanismos."
}

diante la búsqueda de avisos clasificados en un periódico local. En relación a los primeros se utilizaron datos provenientes de los censos nacionales de los años 2001 y 2010 y de la Encuesta de Hogares y Empleo Municipal del año 2018. En lo que respecta a las fuentes de información primaria, se realizaron 22 entrevistas a martilleros y empresarios de la construcción de la ciudad de Tandil, con el objetivo de indagar en las características propias del mercado inmobiliario de la ciudad y en los cambios que se produjeron en la producción de la vivienda desde la salida del modelo de la convertibilidad. Los entrevistados fueron seleccionados en base a sus diferentes niveles de capitalización, tratando de incluir a grandes, medianos y pequeños empresarios; y considerando los distintos rubros a los que se dedican (producción de edificios en altura, edificios de propiedad horizontal, barrios cerrados, viviendas particulares, etc.). Para preservar la identidad de los informantes clave se decidió que en el cuerpo del trabajo los mismos aparezcan mencionados como "Entrevistado 1", "Entrevistado 2", etc. Todas las entrevistas fueron realizadas entre julio y noviembre del año 2017.

A su vez, con el objetivo de tener una mayor aproximación al comportamiento que registraron los precios del suelo a lo largo de este período, se relevaron las ofertas de venta de lotes realizadas en el suplemento semanal "Negocios y Servicios" del periódico local Nueva Era. Si bien la modalidad en la que generalmente se presentan las ofertas dificulta la posibilidad de recabar una buena cantidad de datos, debido a la ausencia de la localización exacta o de los metros cuadrados que poseen los terrenos, los resultados obtenidos permiten visualizar algunas tendencias generales. Asimismo, para analizar lo que sucedió a lo largo del tiempo, se seleccionaron los años 2000, 2005, 2010 y 2015, y, con el fin de poder establecer comparaciones, se trasladaron los precios que aparecían en pesos al valor en el que se encontraba el dólar al momento de publicarse la oferta.

El trabajo comienza recuperando algunas nociones teóricas relacionadas con los factores 
que intervienen en la conformación del precio del suelo urbano y en la distribución residencial de los distintos sectores sociales hacia el interior del espacio urbano. A continuación, se caracteriza brevemente el contexto que surge a nivel nacional luego de la salida del modelo de la convertibilidad y su incidencia en la dinámica de la actividad inmobiliaria y de la industria de la construcción. Luego se analiza los rasgos propios que este proceso adquirió en la ciudad de Tandil y se finaliza con algunas reflexiones.

\section{TEORÍA DE LA RENTA DEL SUELO URBANO Y SEGMENTACIÓN DEL MERCADO DE LA VIVIENDA}

Para abordar el estudio del comportamiento del mercado inmobiliario y de la distribución de los espacios residenciales hacia el interior de las ciudades, se considera pertinente recuperar algunos aportes realizados por exponentes de la Escuela Francesa de Sociología Urbana. Topalov (1984), por ejemplo, considera que el suelo urbano es una mercancía singular porque no es producida socialmente $y$, por lo tanto, su precio no está determinado por el costo de producción. El valor del suelo urbano se define por aquello que se puede realizar en él y el mercado del suelo en las ciudades está conformado por distintos segmentos, que resultan diferentes entre sí. Cada uno de estos segmentos depende de mercados inmobiliarios particulares, en los que predominan tipos de construcciones singulares y en los que la formación de los precios de demanda se rige por leyes diferentes. Por esta razón, el autor menciona que sería necesario avanzar en la definición de una teoría de las rentas, debido a que el suelo, que es un bien sin valor, define su precio no en base a la oferta sino a partir de la valorización que los capitales realizan sobre el mismo.

Esta teoría implica considerar el proceso por el cual luego de la adquisición del suelo urbano es necesaria la intervención de un capital que produzca un cambio de uso, para que este pueda ser utilizado por las diferentes actividades que se desarrollan en la ciudad. Morales Schechinger (2005) indica que el cambio de uso del suelo requiere, en general, de inversiones significativas de capital, que son realizadas por agentes especializados en financiar estas obras y a quienes denomina promotores inmobiliarios. Estos agentes desarrollan un proceso por medio del cual adquieren el suelo, realizan la infraestructura necesaria, construyen edificaciones y las comercializan en el mercado inmobiliario. El precio que finalmente poseen los proyectos generados por estos inversores incluye el costo de la construcción, la provisión de las infraestructuras y de los servicios, más una ganancia media y una ganancia adicional, que adopta la forma de renta y que surge como producto de la singularidad de la mercancía suelo. Esta ganancia adicional será distribuida entre los propietarios del suelo y los promotores inmobiliarios, aunque, según el autor, lo más probable es que sea el propietario quien se quede con la totalidad de la renta, debido a que el mercado se caracteriza por presentar una gran competencia entre demandantes de suelo y una escasez de oferta, que termina beneficiando a los propietarios porque pueden seleccionar a quienes deseen venderles, que serán, por lo general, los que estén dispuestos a ceder este beneficio.

Dependiendo de las relaciones sociales que determinan su distribución, la renta del suelo puede aparecer bajo diversas formas: como precio o alquiler del suelo, como alquiler del inmueble, como plusganancia de promoción o como interés; sin embargo, todas ellas tienen en común el hecho de conformarse a partir de una "plusganancia localizada" que se fija en el suelo donde se forma (Topalov, 1984, p. 11). Desde esta perspectiva, la especulación del suelo puede entenderse como la decisión de los propietarios de ajustar los precios de oferta al nivel de la máxima plusganancia que pueden obtener en un momento determinado, o también anticipándose a una futura transformación de su uso. Mientras que la especulación inmobiliaria está relacionada con una búsqueda, por parte de los constructores capitalistas, en la cual intentan comprar y construir allí donde la diferencia entre la plusganancia realizable y el precio real del suelo sea la mayor posible. 
El consumo de la vivienda resulta un elemento importante de diferenciación social, que incluye no solo a la utilización del espacio construido y las edificaciones e infraestructuras correspondientes, sino también a la localización dentro del espacio urbano. La residencia en estos lugares se constituye en un elemento de estatus para los grupos sociales de altos ingresos:

No por azar, el mecanismo de exclusión de los otros sectores sociales se basa en la renta del suelo urbano. Los capitalistas individuales están dispuestos a pagar una suerte de "impuesto privado" por ocupar estos lugares positivamente connotados, en una cuantía tal que sobrepase las posibilidades de los otros sectores sociales, quienes de esta forma son rechazados. (Jaramillo, 2009, p. 164) ${ }^{2}$

Topalov (1984) menciona que estos espacios dentro de una ciudad corresponderían con el 'mercado de la vivienda privilegiada', donde los precios no estarían regidos por las condiciones de producción, sino por las ubicaciones escasas de estas áreas residenciales, por espacios que no resultan sustituibles y que son socialmente regulados, en tanto allí residen grupos sociales correspondientes a la clase burguesa, que intentan generar representaciones de estatus. Los precios de monopolio que se generan devienen de los escasos lugares que poseen estas cualidades. Vale mencionar que existen diversos mercados de vivienda privilegiada, caracterizados por diferentes precios y posición jerárquica.

Distinto es lo que sucede con la denominada "vivienda normal", a la que Topalov (1984, p. 161) entiende como "aquella que es objeto de una producción capitalista masiva para las capas populares en el período histórico considerado; cumple normas de habitabilidad consideradas mínimas y es construida en ubicaciones no importantes de la aglomeración". Las zonas

2 Este mecanismo de exclusión, según Jaramillo (2009), está ligado a la Renta de Monopolio de Segregación, la cual es inherente a la restricción para el acceso a ciertos lugares residenciales que se realiza sobre la masa trabajadora. Además, el autor explica que el significado de la vivienda difiere de acuerdo a la clase social a la cual se haga alusión, debido a que para el proletariado esta implica un componente de reproducción de la fuerza de trabajo, mientras que para las clases dominantes involucra parte del consumo final de la plusvalía. residenciales que no están ocupadas por la burguesía serían aquellas consideradas como no importantes, específicamente, estos lugares tienen la peculiaridad de ser sustituibles, en contraposición a aquellos que se encuentran determinados por el mercado de la vivienda privilegiada. En estas zonas residenciales se constituye un precio regulador definido por las condiciones de producción de la vivienda. Las diferencias de precios que aparezcan en este tipo de mercado se deben a la compensación de los distintos costos de uso localizado, por eso Topalov (1984, p. 169) lo denomina "precio monopólico de igualación del coste de uso", a diferencia del mercado de la vivienda privilegiada, donde esas variaciones están determinadas según el poder adquisitivo.

Por su parte, Castells (1986) considera que la distribución residencial hacia el interior del espacio urbano se define, entre otras cosas, en función de las rentas, del nivel de instrucción, de la pertenencia étnica y de la fase del ciclo de vida de los sujetos. En este sentido, hablará de segregación urbana cuando la distribución de viviendas entre los grupos sociales posea una fuerte expresión espacial, es decir, cuando exista una tendencia a la organización espacial jerarquizada y con zonas de fuerte homogeneidad social interna. No obstante, es necesario remarcar que si bien esta es una tendencia general, el espacio urbano es el resultado de procesos históricos y de combinaciones particulares de diferentes estructuras sociales que se suceden a lo largo del tiempo. Esto redunda en formas específicas de distribución de las actividades económicas y de las clases sociales en el espacio:

La estratificación y la segregación urbanas no son la proyección directa en el espacio del sistema de estratificación social, sino un efecto de la distribución del producto entre los sujetos y del producto-vivienda en el espacio, así como de la correspondencia entre estos dos sistemas de distribución. Semejante perspectiva exige, pues, deducir la composición del espacio residencial a partir del estudio de su proceso de producción, tanto a nivel de las formas urbanas como la repartición entre ellas de los sujetos. (Castells, 1986, p. 207).

De esta forma, no habría leyes generales que expliquen regularidades geográficas en relación 
a la distribución residencial en el espacio urbano, más bien se generarían combinaciones específicas entre las relaciones de clases y la distribución de la vivienda. Por lo cual, no siempre se visualiza una distribución gradual de los grupos sociales en el espacio urbano según su nivel de renta, ni tampoco existen lugares privilegiados de antemano, debido a que el espacio se redefine de forma continua según la coyuntura de la dinámica social (Castells, 1986).

En síntesis, abordar la producción de espacios residenciales en el contexto de una sociedad capitalista implica comprender cómo se estructuran los diferentes segmentos del mercado de la vivienda (privilegiada y normal) y quiénes participan de la misma, considerando que la particularidad de la mercancía-vivienda conlleva la intervención en el proceso productivo de los propietarios del suelo y la generación de sobreganancias, que surgen a partir de la transformación del mismo. Es interesante considerar los elementos que brinda la teoría de la renta del suelo urbano para analizar lo que ocurrió en las ciudades argentinas, en general, y en Tandil, en particular, a partir de las características que asumió el modelo económico de la postconvertivilidad, donde se generaron condiciones propicias para incrementar significativamente las rentas extraordinarias obtenidas a partir de los cambios de uso del suelo y de las inversiones inmobiliarias dirigidas a determinados tipos de formatos residenciales y turísticos.

\section{ProducCIÓN DE LA VIVIENDA Y MERCADO DEL}

SUELO EN LA CIUDAD DE TANDIL EN EL PERIODO POSCONVERTIBILIDAD

En la Argentina, luego de la crisis que terminó con el modelo económico de la convertibilidad, entre los años 2001 y 2002, se experimentó una recuperación económica de gran importancia, a raíz de decisiones políticas vinculadas a la reconstrucción del mercado interno y a la regeneración de las fuentes de empleo. Específicamente, la política económica que posibilitó superar la recesión se caracterizó por la definición de un tipo de cambio de dólar competitivo, bajas tasas de interés y una activa participación del Estado en pos de dinamizar ciertos sectores productivos. En este contexto, las ciudades desempeñarían un papel fundamental en el nuevo ciclo de acumulación del capital, constituyéndose en lugares privilegiados para la generación y apropiación de rentas (Harvey, 2012).

Diferentes trabajos de investigación, como los de Baer (2011), Fernández Wagner (2014) y Del Río (2014), dan cuenta del papel que cumplieron los espacios urbanos argentinos en este período. La fuerte recuperación de la actividad de la construcción, resultó uno de los puntales para la generación de empleos, la reactivación económica y la recomposición del mercado interno. Sin embargo, este efecto dinamizador en la economía estuvo acompañado por un proceso de valorización diferencial del suelo hacia el interior de las ciudades (Baer, 2011), que incrementó las desigualdades y expulsó del mercado inmobiliario formal a una mayor proporción de la masa trabajadora y explotada. De esta forma, a pesar de que se promovieron importantes iniciativas para regenerar el tejido social y económico mediante la activa intervención del Estado, persistió una fuerte limitación en cuanto al "derecho a la ciudad" (Lefebvre, 1969), debido a que se consolidaron las lógicas que promovieron la producción del suelo urbano con el fin de valorizar capitales e incrementar la apropiación de rentas, en detrimento de las posibilidades de satisfacer las necesidades habitacionales de la población trabajadora.

Reese (2006) menciona que si bien este momento de expansión de la actividad económica permitió reducir el desempleo y los niveles de pobreza, no logró modificar la tendencia a la segregación espacial que se venía registrando en las ciudades grandes e intermedias del país en las décadas anteriores. El autor manifiesta que el crecimiento de la actividad de la construcción y la mayor demanda de suelo urbano desencadenaron una importante transferencia de rentas que benefició a los propietarios de las tierras y, además, dieron lugar a importantes procesos especulativos. La progresiva distancia que se 
registró entre los ingresos de la población trabajadora y el precio del suelo urbano y de los inmuebles, dio como resultado un incremento de la informalidad urbana. De esta manera, si bien existió una preocupación desde el Estado nacional por el desarrollo de una política habitacional de gran alcance, no se establecieron mecanismos para regular el mercado inmobiliario y contener los efectos negativos que generó la especulación (Catenazzi y Reese, 2013).

En esta misma línea de razonamiento, Segura (2014) sostiene que la continuidad del modelo de urbanización excluyente en las metrópolis latinoamericanas durante la primera década del siglo XX, limitó los efectos que conllevaron las políticas de redistribución del ingreso aplicadas por varios países de la región. Esta situación se explica, en gran medida, debido a que la configuración espacial de las ciudades no constituye solo un reflejo de las desigualdades presentes en la sociedad, sino que además actúa consolidando mecanismos que reproducen y profundizan dichas desigualdades. De este modo, al no cuestionarse los instrumentos que limitan el acceso al suelo urbano, los procesos de segregación se profundizaron aún en estos períodos de limitada redistribución del ingreso. Coincidiendo con este diagnóstico, Baer (2008) indica la necesidad estratégica de que los organismos públicos diseñen políticas territoriales dirigidas al control de los precios del suelo urbano, que permitan facilitar la adquisición y el arrendamiento de las viviendas. Estas medidas, además, deberían ser acom- pañadas por instrumentos que permitan apropiarse de la renta generada mediante la inversión pública y que, generalmente, es captada por los propietarios de la tierra y de los inmuebles.

Al analizar lo ocurrido en Tandil, se observa que la ciudad experimentó este mismo proceso en los últimos quince años, coexistiendo un fuerte dinamismo de la actividad de la construcción con una creciente conflictividad social vinculada a las dificultades que encontró una proporción cada vez mayor de la masa trabajadora para acceder a la vivienda digna. Además, se observó un aumento de los tenedores de vivienda inversores, es decir, un incremento de propietarios que adquirieron inmuebles como bienes de cambio, en detrimento de aquellos que lo hicieron para satisfacer una necesidad uso (Auguste y Seffino, 2013). Según datos de los Censos Nacionales, la cantidad de viviendas en Tandil se incrementó en un 22,84\% entre 2001 y 2010 (de 41.067 a 50.450 unidades), mientras que la población en ese mismo período creció en un $14,6 \%$. Sin embargo, a pesar del aumento del número de viviendas, los propietarios descendieron de un $70,4 \%$ a un $62,6 \%$, mientras que los inquilinos crecieron del $15,5 \%$ al 24,5\% de la población (INDEC, 2001; 2010). Por su parte, de acuerdo a la Encuesta de Hogares y Empleo Municipal, en el año 2018 los propietarios de las viviendas continuaron descendiendo en Tandil, hasta alcanzar un 57,6\%, mientras que los inquilinos treparon al $30 \%$ (Tabla 1) (El Eco de Tandil, 21/09/2019).

Tabla 1. Régimen de tenencia de las viviendas en Tandil. Años 2001, 2010 y 2018

\begin{tabular}{lccc}
\hline Régimen de tenencia & 2001 & 2010 & 2018 \\
\hline Propietario de vivienda y terreno & $70,4 \%$ & $62,6 \%$ & $57,6 \%$ \\
\hline Propietario solo de la vivienda & $1 \%$ & $1,4 \%$ & $3,1 \%$ \\
\hline Inquilino & $15,5 \%$ & $24,5 \%$ & $30 \%$ \\
\hline Ocupante por préstamo & $7,8 \%$ & $6,3 \%$ & $6,8 \%$ \\
\hline Ocupante por trabajo & $3,5 \%$ & $3,3 \%$ & Sin información \\
\hline Otro & $1,9 \%$ & $2 \%$ & $1,7 \%$ \\
\hline
\end{tabular}

Fuente: INDEC (2001; 2010) y El Eco de Tandil (21/09/2019) 
Asimismo, los espacios residenciales que se generaron en este último período presentan particularidades en los diferentes ejes de crecimiento de la ciudad. Por un lado, es posible observar que en el sur se produjo una proliferación de emprendimientos inmobiliarios que podrían encuadrarse dentro del mercado de la vivienda privilegiada (Topalov, 1984), como también de proyectos para la actividad turística y recreativa. Esta zona coincide con la ubicación de las sierras, que en este último período han sido valorizadas como recurso paisajístico, lo que ha posibilitado a los inversores inmobiliarios generar diversos proyectos que se valorizan mediante la incorporación de elementos del medio natural. La construcción de estos espacios residenciales en los faldeos serranos requiere de la transformación del paisaje, que a menudo implica efectos negativos sobre el ambiente, como la eliminación de la cubierta vegetal, la impermeabilización del suelo y modificación de los cursos de agua que nacen en las cotas más altas. En los últimos años, como consecuencia de estas alteraciones, también han emergido una serie de problemas relacionados con las inundaciones que afectan a determinados lugares del ejido urbano (Fernández Equiza, 2017).

El primer barrio cerrado de la ciudad, "Sierras de Tandil", comenzó a construirse en la década de 1990 y, en los años 2000, se originó un nuevo proyecto denominado "Altos Aires", que se desarrolló en un predio de 160 hectáreas y que contó con unos 400 lotes de 2.000 metros cuadrados cada uno (Lan, Linares. Di Nucci y López Pons 2010). De forma paralela, proliferaron otros espacios residenciales en el sur de la ciudad, enmarcados en lo que el Plan de Desarrollo Territorial denomina "Barrios Parque"3 y "Urbanizaciones Especiales"4. En general, estos proyectos se comercializan me-

3 Según el Plan de Desarrollo Territorial del año 2005, los Barrio Parque son sectores dotados parcialmente de infraestructura y destinados exclusivamente a la residencia unifamiliar, con características particulares, como las de poseer tejido abierto y muy bajas densidades de ocupación.

4 Las urbanizaciones Especiales comprenden emprendimientos residenciales, privados o públicos, que incluyen la construcción de la totalidad de las edificaciones y la dotación de infraestructura y equipamiento comunitarios en predios mayores a una hectárea. diante estrategias de marketing, que ofrecen estilos de vida asociados a la tranquilidad, la seguridad y la posibilidad de disfrutar de la naturaleza.

Por su parte, el centro histórico y comercial de la ciudad evidenció un proceso de verticalización y densificación urbana sin precedentes. Lan et al. (2010) señalan que entre las décadas de 1960 a 1990 se construyeron 21 edificios con más de cinco pisos, mientras que entre los años 2000 y 2009 ese número se elevó a 27, representando un crecimiento del $129 \%$ en tan solo 10 años.

A su vez, el espacio comprendido por las periferias noroeste, norte y noreste, donde reside mayormente la masa trabajadora, se constituyó en el destinatario de gran parte de los programas habitacionales desarrollados por los distintos niveles del Estado. Sin embargo, a pesar de que los recursos invertidos en políticas de viviendas crecieron notoriamente entre los años 2003 y 2015, se evidenciaron cada vez mayores dificultades para acceder a un hábitat digno, ya sea a través del mercado formal o por medio de una solución brindada por un programa estatal. En este contexto, se produjeron masivas usurpaciones de terrenos y de conjuntos habitacionales que aún no estaban concluidos (Campos, Castiglioni, Herrera y Valente Ezcurra, 2012). Estos hechos están relacionados con la paralización de las obras de algunos programas y la incertidumbre generada con respecto a sus posibilidades de finalización.

Lan et al. (2010) indican que los procesos especulativos desatados en torno al suelo urbano desde comienzos de la década anterior, han contribuido a agravar las desigualdades territoriales prexistentes. Un ejemplo ilustrativo de esta situación, es que los precios de los inmuebles en venta con tres habitaciones entre los años 2005 y 2009 se incrementaron un 176\% en promedio, pero hacia el interior de la ciudad las diferencias resultan notables. Mientras en algunas áreas residenciales extraurbanas del sur del ejido urbano se registraron aumentos de hasta el $213 \%$, en los barrios en proceso de consolidación y consolidados del noroeste, norte y noreste de la ciudad, el crecimiento alcanzó un 100\%. De esta forma, una vivienda con tres habitacio- 
nes en el año 2009 alcanzaba valores de U\$S Aguirre o Movediza (Mapa 1), estos inmuebles 250.000 en los faldeos serranos, pero en Villa descendían a U\$S 40.000.

Mapa 1. Tandil. Ubicación de las sierras, principales barrios y vías de acceso a la ciudad
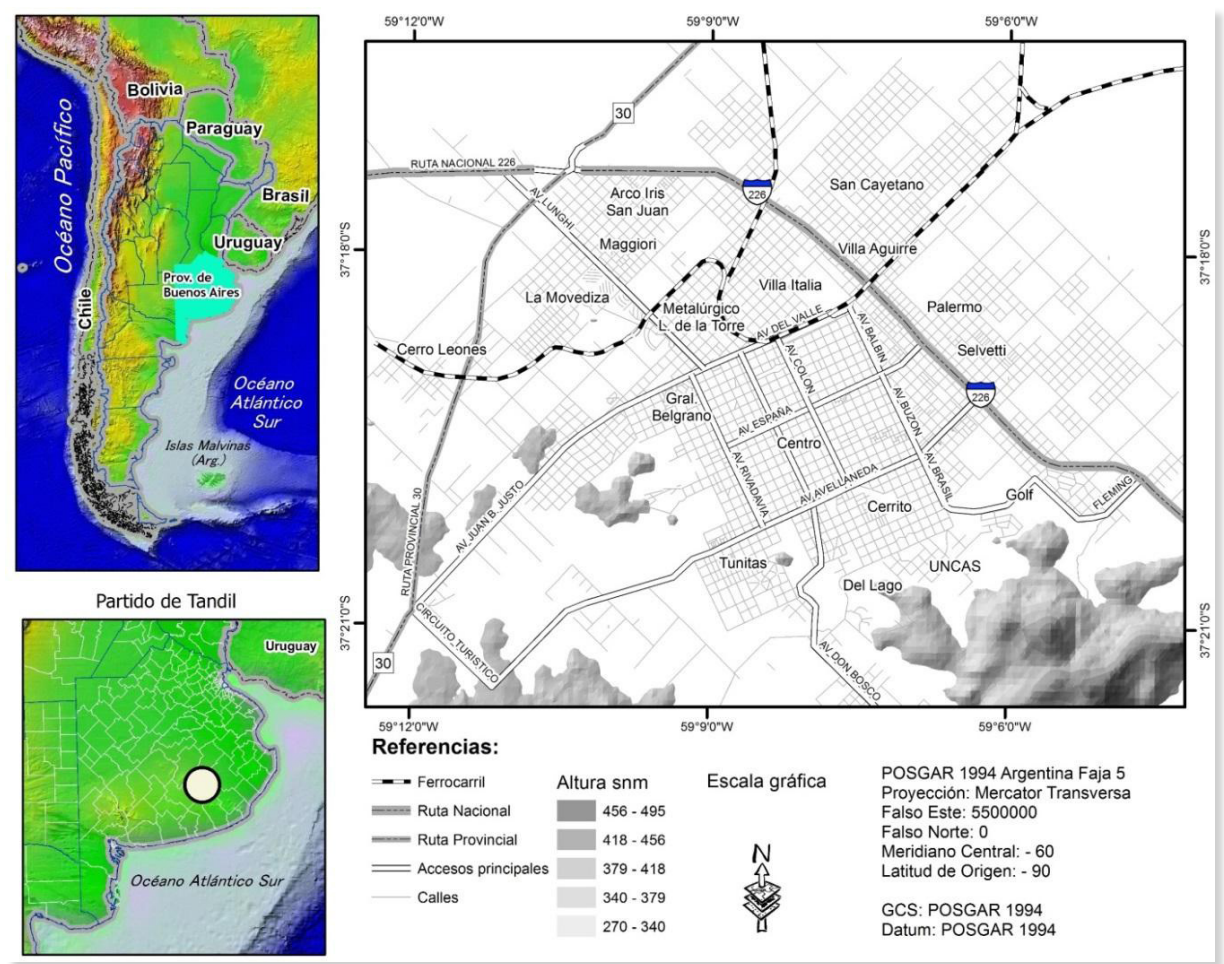

Fuente: Lan (2011, p. 31)

En definitiva, en la ciudad de Tandil en un período caracterizado por el crecimiento de la actividad inmobiliaria y de la construcción, y con una mayor inversión por parte del Estado en políticas habitacionales, se registró un incremento de la conflictividad en relación al acceso al hábitat. Por lo tanto, al igual que en el resto de las ciudades argentinas, en mayor o menor medida, puede observarse un creciente problema relacionado con la emergencia de un modelo urbano donde se han fortalecido aquellas lógicas que producen el suelo con fines rentísticos, dejando en evidencia que el crecimiento económico y la redistribución del ingreso no implica necesariamente mayores posibilidades de acceso a la vivienda para la población trabajadora.

\section{EL AUGE INMOBILIARIO Y LA ESPECULACIÓN EN TANDIL SEGÚN LOS ACTORES DEL MERCADO}

La mayoría de los martilleros y los empresarios de la construcción entrevistados coinci- dieron que en Tandil se produjo un importante crecimiento inmobiliario luego de la salida de la convertibilidad. Al indagar sobre las razones que explican esta situación, los informantes clave reconocieron factores relacionados con el contexto nacional y otras variables de orden local. Dentro de los primeros, se destacó la recuperación económica que experimentó el país luego de la crisis de los años 2001-2002 y, en lo que respecta a las segundas, se enfatizó en la relativa cercanía que posee la ciudad con respecto a la Región Metropolitana de Buenos Aires (en adelante RMBA), además de la diversidad de su estructura económica, la calidad de vida, el impulso que registró la actividad turística y la presencia de diferentes instituciones de enseñanza superior.

Algunos entrevistados mencionaron que en los primeros años que sucedieron a la salida de la convertibilidad se generaron determinadas condiciones que permitieron alcanzar altos grados de previsibilidad frente a las inversio- 
nes realizadas. Concretamente, se destacan los bajos niveles de inflación predominantes hasta el año 2007 y el incremento de la demanda de inmuebles destinados tanto a la inversión como al uso. Por ejemplo, el Entrevistado 1 afirmó que el auge de la construcción se produjo entre, aproximadamente, los años 2005 y 2013. Las razones que impulsaron el crecimiento de este sector, según su perspectiva, pueden encontrarse en las altas tasas de rentabilidad que generaba la actividad en ese momento, provocando que muchas inversiones se volcaran hacia este sector. Otro dato fundamental que destacó el entrevistado es que el crecimiento se caracterizó por la proliferación de complejos de departamentos, debido a que era la inversión que generaba mayores beneficios. Esta situación también implicó una modificación en el perfil del mercado inmobiliario de la ciudad con respecto a décadas anteriores, donde lo habitual era que una familia o persona comprara un terreno $y$ luego construyera su vivienda. Los cambios en la composición de los núcleos familiares (menos numerosos) y la menor capacidad adquisitiva de los salarios en comparación con el valor de los bienes inmuebles, generaron que una parte de la población considerara la posibilidad de residir en departamentos. Otro factor adicional que colaboró para la proliferación de los complejos, es la importante demanda ejercida por el sector estudiantil universitario. De esta forma, los terrenos del centro del ejido urbano comenzaron a valorarse de acuerdo a la cantidad de departamentos que era posible realizar en ellos, lo cual condujo a una importante alza de precios. Este escenario resultó claramente beneficioso para los constructores, pero no para quienes deseaban acceder a una vivienda propia. Los inmuebles unifamiliares en aquel entonces encontraron cada vez mayores dificultades para venderse, a diferencia de los departamentos que mantuvieron constante su demanda.

Según este mismo entrevistado, a partir de 2013, aproximadamente, se ingresó en un período de amesetamiento que obedeció, entre otras causas, al incremento de los costos en la reali- zación de las obras, a los menores márgenes de ganancia y al inicio de un período de estancamiento económico. Esto fue acompañado también por un aumento en el precio de la mano de obra, debido a que, según el mismo informante, los organismos estatales y los sindicatos comenzaron a realizar controles más estrictos de las condiciones de trabajo, con lo cual los empresarios debieron regularizar las condiciones de trabajo de la mayor parte de sus empleados.

A su vez, un segundo grupo de entrevistados, reconocen la incidencia del contexto nacional en la dinámica de la actividad inmobiliaria, pero remarcaron con mayor énfasis los aspectos locales como responsables del desarrollo del sector. Por ejemplo, el Entrevistado 2, subrayó la importancia que la ciudad adquirió para la región en las últimas décadas, destacando la solidez de algunos sectores económicos, como el agropecuario, la cuenca lechera, la industria metalúrgica, el turismo y, más recientemente, la industria del software. Por su parte, la totalidad de los entrevistados resaltó la importancia que tuvo para el crecimiento del sector inmobiliario la migración de personas provenientes de la RMBA u otras grandes ciudades del país. En este punto, se establece una relación con la actividad turística, que permitió un mayor conocimiento del lugar y generó que algunos de los visitantes, durante su estadía, realicen consultas sobre la posibilidad de residir de forma permanente, atraídos por la calidad de vida $y$, principalmente, por los menores problemas de inseguridad que se registran en comparación con las grandes urbes. En varias oportunidades se mencionó que algunas personas provenientes de la RMBA migran hacia Tandil pero conservan sus fuentes laborales, realizando movimientos pendulares todas las semanas, de lo cual se deduce que, en los últimos años, con la consolidación de determinados avances en materia de tecnología y transporte, surgieron nuevas relaciones con otras ciudades, $y$, especialmente, con la RMBA.

La percepción que poseen los entrevistados puede ser contrastada con algunas fuentes de información secundaria. Por ejemplo, El Gráfico 
1 muestra el índice de actividad del sector inmobiliario de la provincia de Buenos Aires entre 2001 y 2015 , donde se visualiza un crecimiento sostenido hasta el año 2008, luego una breve caída, a la que le sigue una importante recupe- ración hacia el año 2011, para ingresar posteriormente en un período de amesetamiento. Lo mismo sucede con el Gráfico 2, que da cuenta del índice de la Actividad de la Construcción entre enero de 2003 y julio de 2017.

Gráfico 1. Índice de Actividad del Sector Inmobiliario de la provincia de Buenos Aires. Base $1^{\circ}$ semestre de 2001 $=100$. Período: $1^{\circ}$ semestre de 2001- $1^{\circ}$ semestre de 2015

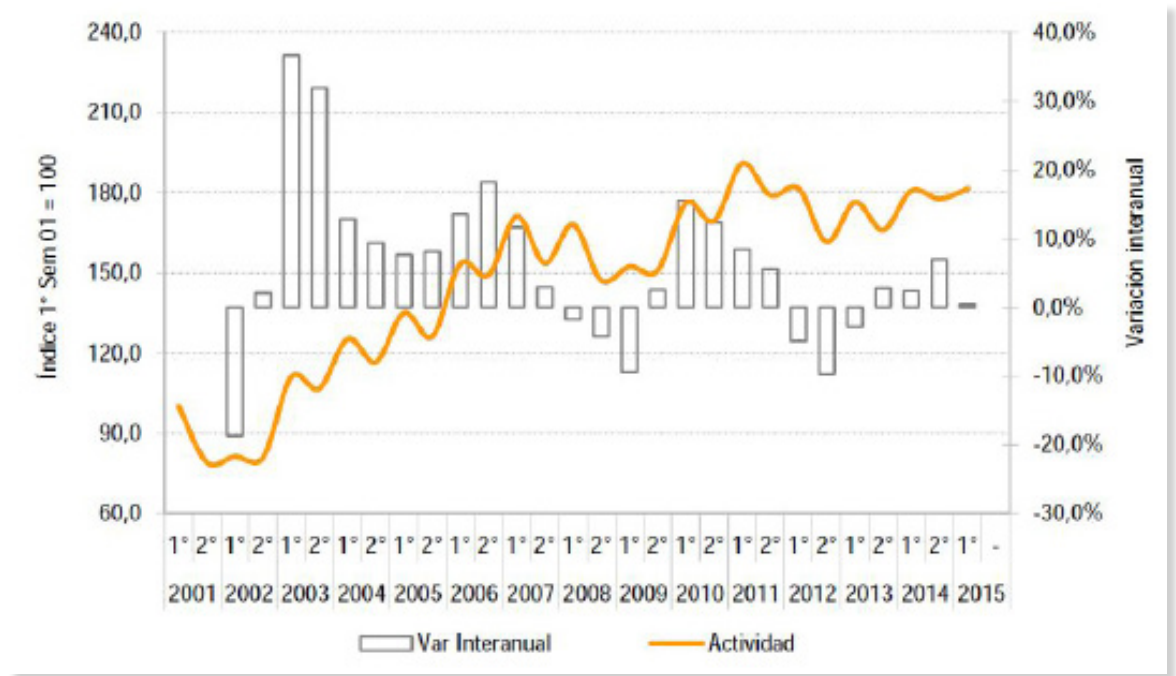

Fuente: Dirección Provincial de Estadística (2015)

Gráfico 2. Índice Provincial de la Actividad de la Construcción, enero de 2003 a julio de 2017. Base enero 2003=100

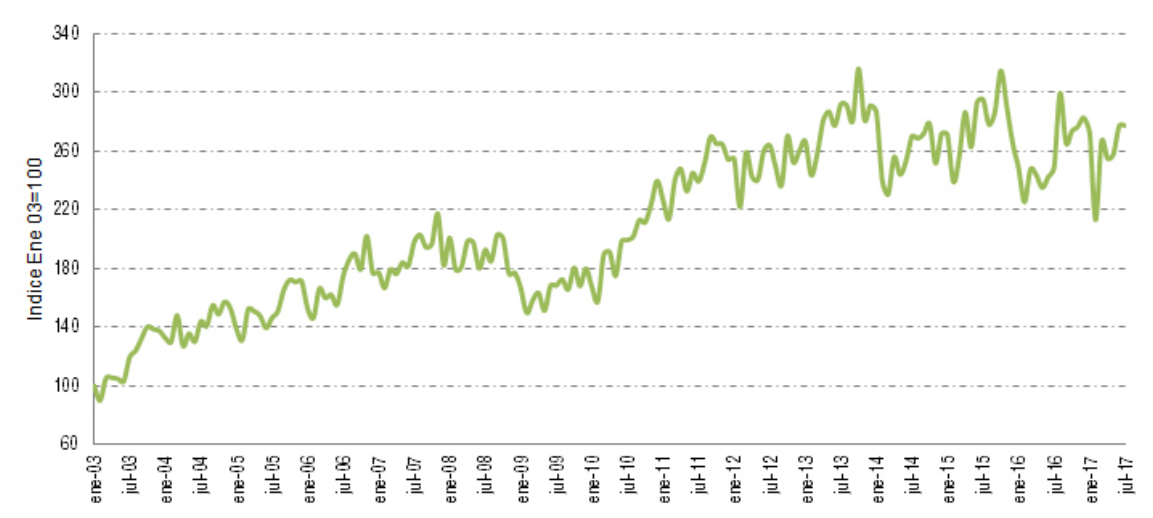

Fuente: Dirección Provincial de Estadísticas (2017)

En lo que respecta a las razones que generaron un freno en el dinamismo del sector, una buena parte de los entrevistados ponderó fuertemente la restricción a la libre compra de divisas que se implementó en el Gobierno de Cristina Fernández de Kirchner, hacia el año 2011. Sin embargo, cuando esa normativa fue eliminada, en diciembre del año 2015, no se registró un nuevo perío- do de crecimiento prolongado, sino una breve reactivación en el año 2017, que se correspondió con el lanzamiento de los créditos hipotecarios ajustados por inflación, la cual finalizaría rápidamente a raíz del complejo escenario económico en el que se ingresó a partir de mayo del año 2018 (El Eco de Tandil, 1/07/2018). En este sentido, parece tener más asidero la explicación 
esbozada por el Entrevistado 1, quien mencionó que el momento de auge de la actividad inmobiliaria correspondió con un ciclo en el cual la actividad de la construcción generó ganancias extraordinarias en el conjunto de la economía y, por esta razón, había logrado atraer inversiones provenientes de diversos sectores. Finalmente, cuando la economía nacional ingresó en un período de amesetamiento, hacia el año 2012, ese ciclo comenzó a mostrar signos de agotamiento.

En síntesis, más allá de las singularidades que posee la ciudad de Tandil y la región, que colaboraron para sostener, en las últimas décadas, niveles de actividad que se encontraron por encima de la media nacional, se considera que efectivamente existió un ciclo de expansión de los sectores inmobiliario y de la construcción, que se forjó como consecuencia de los cambios generados en la política económica argentina, a partir de la salida de la crisis de los años 2001 y 2002. Las ganancias extraordinarias obtenidas en las inversiones destinadas a la generación de bienes inmuebles y la expansión de la obra pública fueron las responsables de este auge, que, asimismo, trajo aparejado un importante cambio en el perfil del tipo de viviendas producidas por los capitales constructores y en las posibilidades de acceso para las diferentes clases sociales.

\section{VALORIZACIÓN DIFERENCIAL DEL SUELO URBANO Y DE LAS VIVIENDAS EN EL ESPACIO INTRA-URBANO DE LA CIUDAD DE TANDIL}

Al indagar en las variables que inciden sobre la valorización del suelo en los diferentes lugares de la ciudad, el Entrevistado 3 señaló que en el centro de la ciudad los lotes se cotizan en base al tamaño, a la ubicación y también a la cantidad de departamentos que es posible realizar en ellos. El informante clave también mencionó que la implementación del Plan de Desarrollo Territorial, en 2005, resultó determinante porque valorizó aún más las parcelas ubicadas dentro de lo que se denomina como "Zona Central" (delimitada por las avenidas España y Santamarina y las calles 14 de julio y Maipú) y, al mismo tiempo, bajó el perfil del segundo anillo céntri- co, es decir, de los terrenos que se ubican por fuera de este cuadrante, ya que la normativa urbanística impide realizar construcciones que superen los 16,5 metros de altura en este sector.

Por su parte, el Entrevistado 4 identificó tres categorías de lotes dentro de la ciudad:
En lo que es lote hay tres categorías: está una categoría de un gran nivel, de los que por ahí pueden acceder a lotes, a lo mejor, de valores importantes; hay lotes bien ubicados que tienen un valor por el desarrollo que per- miten, por la cantidad de departamentos y unidades que se pueden hacer; $y$, después, están lotes de inferiores va- lores que son los valores más bajos que tenemos en tie- rras en Tandil. Están esos tres grupos. (Entrevistado 4, 23/08/2017)

Los terrenos de gran nivel, a los que hace referencia el entrevistado, en general, son aquellos que se ubican en la parte sur del ejido urbano, en los faldeos serranos o en los barrios cercanos a estos. De igual modo, el Entrevistado 5 marcó una diferencia entre aquellas parcelas que son demandadas por sus condiciones de accesibilidad a diferentes puntos de la ciudad y ciertos lotes exclusivos, que son valorados por encontrarse en lugares que otorgan determinado prestigio social y en los que Topalov (1984) identificaría la conformación de un mercado de la vivienda privilegiada. Según aclaró este informante clave:

\section{A la gente que pertenece a un determinado sector social no le importa ir a construir en las sierras, le encanta el lugar y lo hace. Pero cuando ya son de un menor poder adquisitivo buscas otra cosa, el acceso, los servicios. (En- trevistado 5, 09/08/2017)}

Además de los lotes de la parte sur del ejido urbano, también los departamentos ubicados en edificios de categoría pueden considerarse dentro del Mercado de la Vivienda Privilegiada (Topalov, 1984). Según lo expresado por el Entrevistado 6,en un edificio horizontal de primera categoría el valor del metro cuadrado asciende a 3.000 dólares, similar a lo que sucede en algunos barrios de la Ciudad Autónoma de Buenos Aires, como Caballito, Belgrano, Palermo o Recoleta. También mencionó que un departamento ubicado en un edificio exclusivo a punto de inaugurarse, frente a la plaza central de Tandil, costaba 400.000 dólares (4.000 dólares el metro 
cuadrado). Pero también en su inmobiliaria se comercializan otros departamentos que rondan los 90.000 o 100.000 dólares, es decir, 1.500 dólares el metro cuadrado, los cuales resultan los más demandados por los inversionistas.

A su vez, para graficar la magnitud de la suba del valor de los inmuebles, el Entrevistado 6 mencionó el caso de unos departamentos que ofrecía para vender en su inmobiliaria, de 40 metros cuadrados, ubicados a cinco cuadras del centro comercial y que se cotizaban, en 2017, a 60.000 dólares. Estos mismos departamentos ya habían sido comercializados por él mismo hace diez años atrás, cuando se estrenaron, pero a un precio de 20.000 dólares. También el Entrevistado 7 explicó la incidencia que la ubicación posee en el valor de las propiedades, mencionando que un departamento a estrenar de dos ambientes, de 50 metros cuadrados, ubicado en el centro comercial de la ciudad, se cotizaba, en 2017, en aproximadamente 100.000 dólares. Sin embargo, un departamento de similares características en la zona de "La Terminal" (a quince cuadras del centro comercial) podía venderse a alrededor 60.000 dólares.
Resulta interesante contrastar esta información brindada por los informantes clave con los datos obtenidos a partir del relevamiento de los precios del suelo urbano realizado mediante los avisos clasificados del periódico "Nueva Era". Adicionalmente, durante el año 2000 en el suplemento apareció, en varias oportunidades, un cuadro en el cual se estimaban los precios promedio de venta para viviendas de 2, 3 y 4 habitaciones en los distintos barrios de la ciudad. Con esa información se confeccionó el Mapa 2, donde se visualizan los rangos de precios estimados para viviendas de dos habitaciones en cada lugar. Según estos datos, el barrio que presentaba, en aquel entonces, los valores más altos era el Golf, donde una vivienda de dos habitaciones podía alcanzar un precio de hasta U\$S80.000, seguido por el Cerrito, el Centro y los lugares cercanos a este último. A su vez, los valores más bajos se encontraban en el barrio Movediza, en Villa Aguirre y en la zona de La Rural. No aparece mencionado el barrio Tunitas, que ya en ese momento era un lugar altamente estigmatizado, en términos negativos, dentro de la ciudad.

Mapa 2. Rangos de precios promedio de viviendas de dos dormitorios en venta, por barrios de la ciudad de Tandil. 10 de enero de 2000

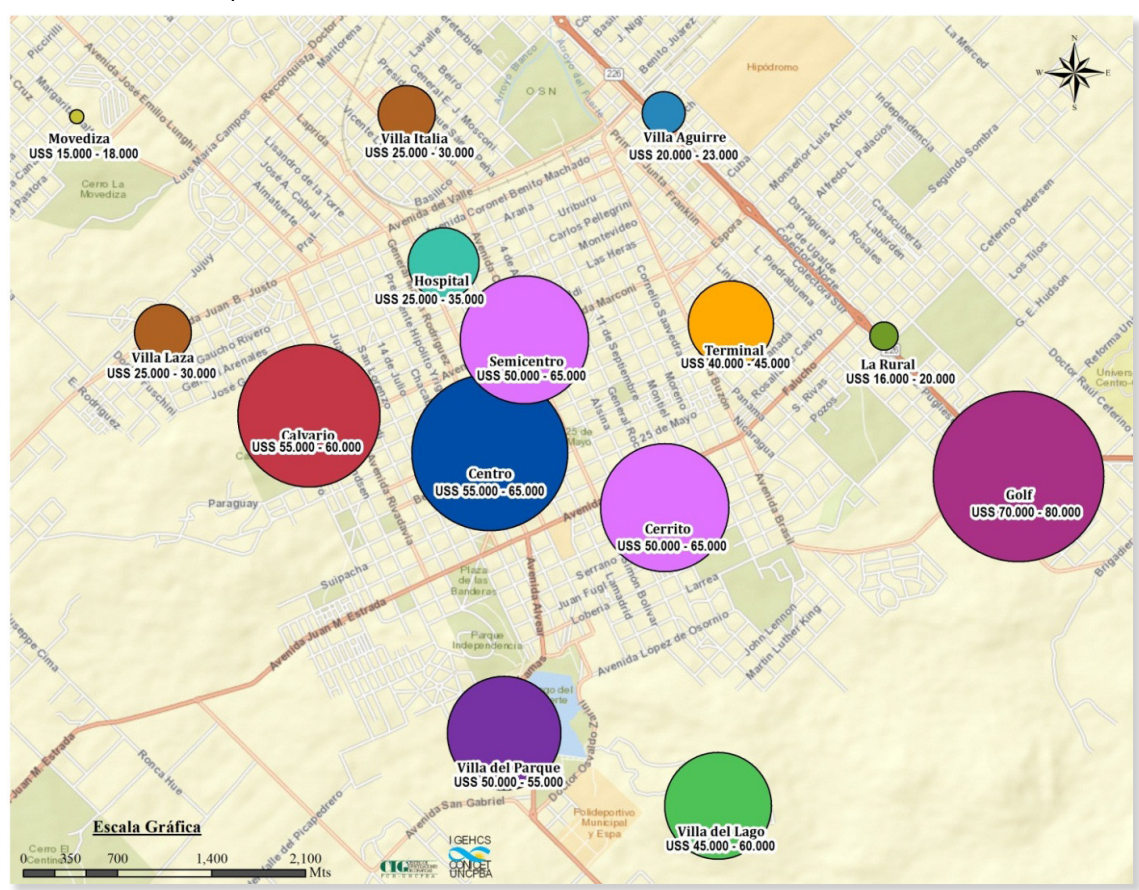

Fuente: elaboración personal con base en datos del suplemento "Negocios y Servicios” del periódico Nueva Era (10/01/2000, p. 2) 
Por su parte, en el Mapa 3 se observa el precio del metro cuadrado de los terrenos en venta para el año 2000. En este caso, los valores oscilaban entre 3 y 103 dólares el metro cuadrado. Los lotes más valorizados se ubicaban al sur y centro del ejido urbano, siendo los barrios Cerrito y Uncas los que concentraban la mayor cantidad de avisos. Los barrios pertenecientes a las periferias noreste (San Cayetano, Villa Aguirre, Palermo y Selvetti), noroeste (Arco Iris, San Juan y Maggiori) y el barrio Tunitas, contaban con muy pocos datos y todos ellos con precios relativamente bajos.

Mapa 3. Precio del suelo (metro cuadrado/dólares) en la ciudad de Tandil, año 2000

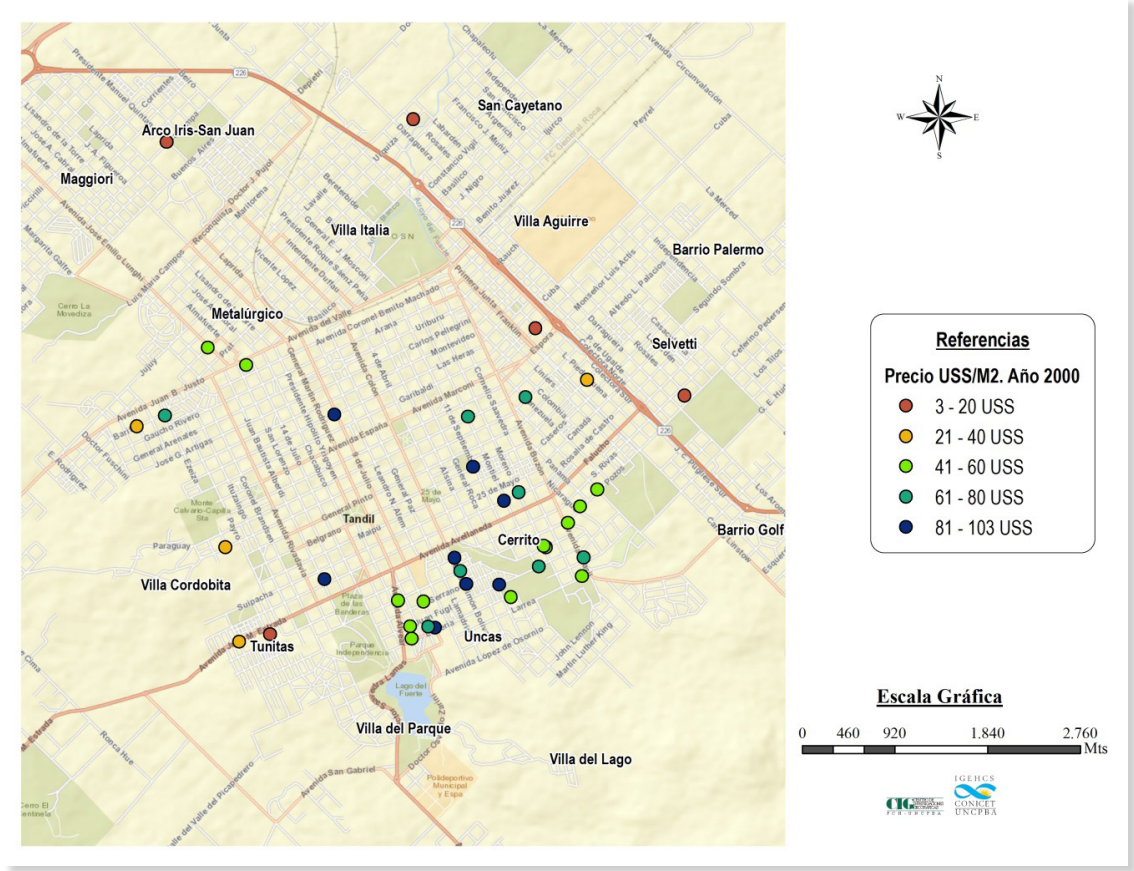

Fuente: elaboración personal con base en ofertas realizadas por las inmobiliarias en el suplemento "Negocios y Servicios" del periódico Nueva Era, año 2000

Para el año 2005, según se aprecia en el Mapa 4 , el rango de valores no varió demasiado con respecto al 2000, fluctuando entre 4 y 106 dólares el metro cuadrado. Tampoco se observan diferencias significativas en lo que se refiere a la distribución de esos valores hacia el interior de la ciudad. Aunque sí aparece una mayor cantidad de datos correspondientes a los barrios periféricos y menos valorizados, a los que se suman, además de los mencionados para el año 2000, La Movediza y Villa Laza, ubicados en el noroeste del ejido urbano.

Sin embargo, para el año 2010 se percibe que los precios se incrementaron notablemente, alcanzando un máximo de 188 dólares el metro cuadrado. Como se visualiza en el
Mapa 5, los valores más altos se registraron en el centro de la ciudad, mientras que los de los siguientes rangos, también mucho más elevados que en el año 2005, se ubicaron en los barrios del sur, especialmente Uncas y Cerrito, a los que se adicionó también el barrio Golf. La periferia norte continuó mostrando una densidad importante de ofertas, aunque de bajos valores relativos. Este último dato puede explicarse debido a la mejora relativa del poder adquisitivo de la población trabajadora durante los años precedentes, que comenzaron a demandar parcelas para la construcción de viviendas como bien de uso, lo cual incentivó a los propietarios de terrenos en la periferia norte a fraccionarlos $y$ venderlos. 
Mapa 4. Precio del suelo (metro cuadrado/dólares) en la ciudad de Tandil, año 2005

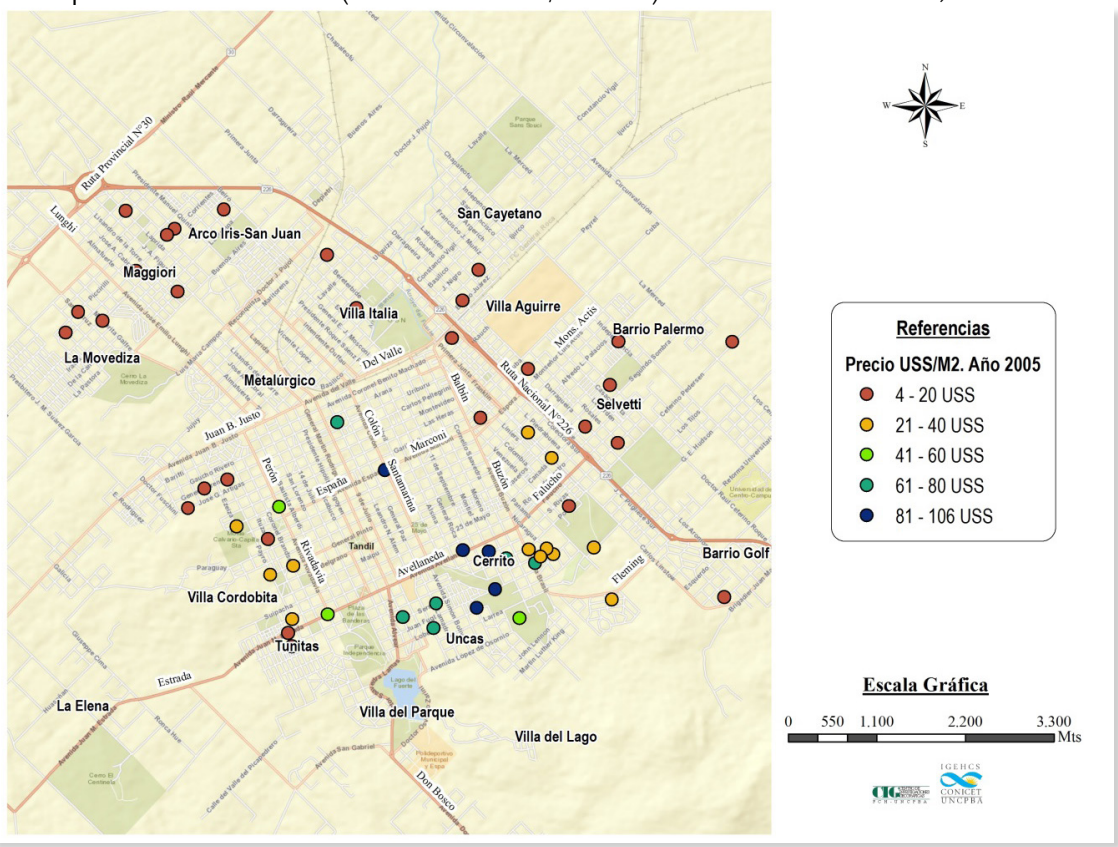

Fuente: elaboración personal con base en ofertas realizadas por las inmobiliarias en el suplemento "Negocios y Servicios" del periódico Nueva Era, año 2005

Mapa 5. Precio del suelo (metro cuadrado/dólares) en la ciudad de Tandil, año 2010

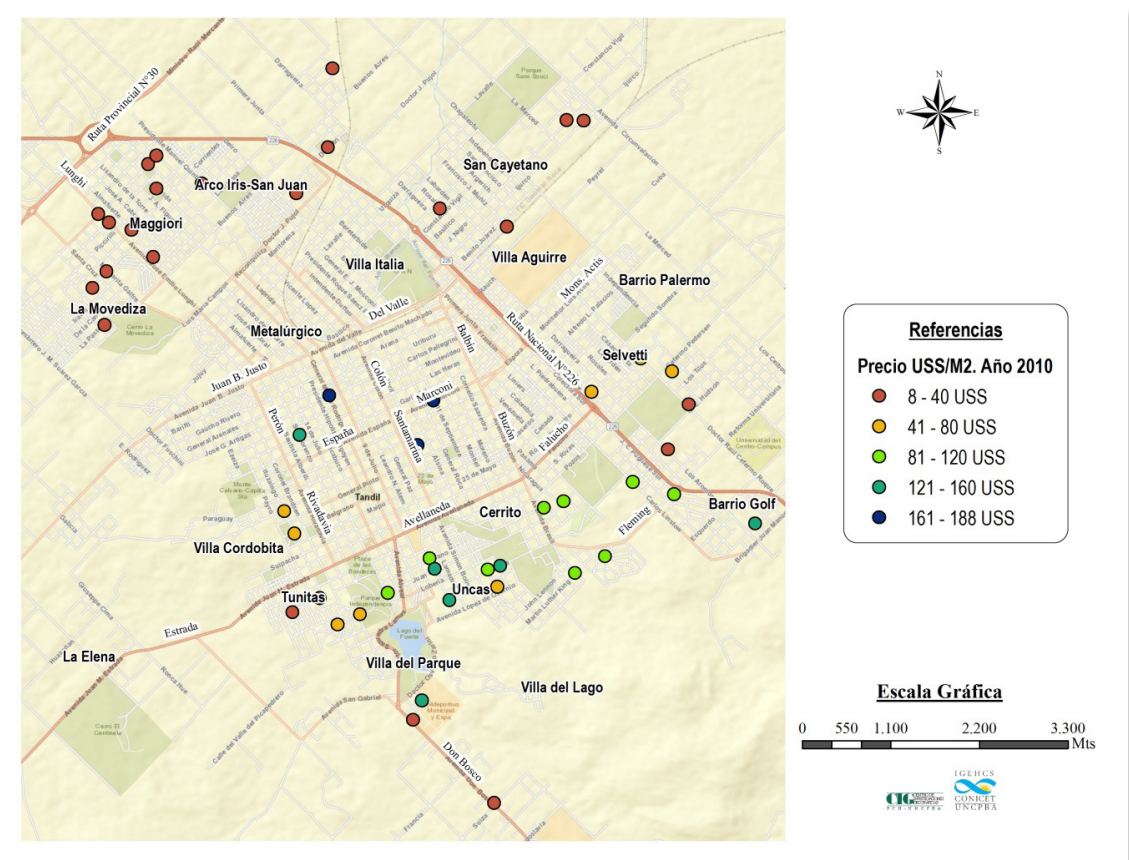

Fuente: elaboración personal con base en ofertas realizadas por las inmobiliarias en el suplemento "Negocios y Servicios" del periódico Nueva Era, año 2010

En el período 2010-2015, según el Mapa 6, el crecimiento de los precios resultó, incluso, superior al del quinquenio precedente. Los lotes más valorizados continuaron ubicándose en el centro y sur de la ciudad, registrando valores máximos que, en el año 2015, alcanzaron los 447 dólares el metro cuadrado. En las periferias noroeste-norte-noreste el incremento también tuvo una gran relevancia, ya que mientras que en el año 2010 en estos barrios 
todas las ofertas relevadas oscilaron entre 4 y 40 dólares el metro cuadrado (a excepción de Selvetti donde se registraron lotes de entre 41 y 80 dólares el metro cuadrado), en 2015 los valores se ubicaron entre 28 y 160 dólares el metro cuadrado ( $y$ en Selvetti algunos lotes se ubicaron en el rango de entre 161 y 240 dólares el metro cuadrado).

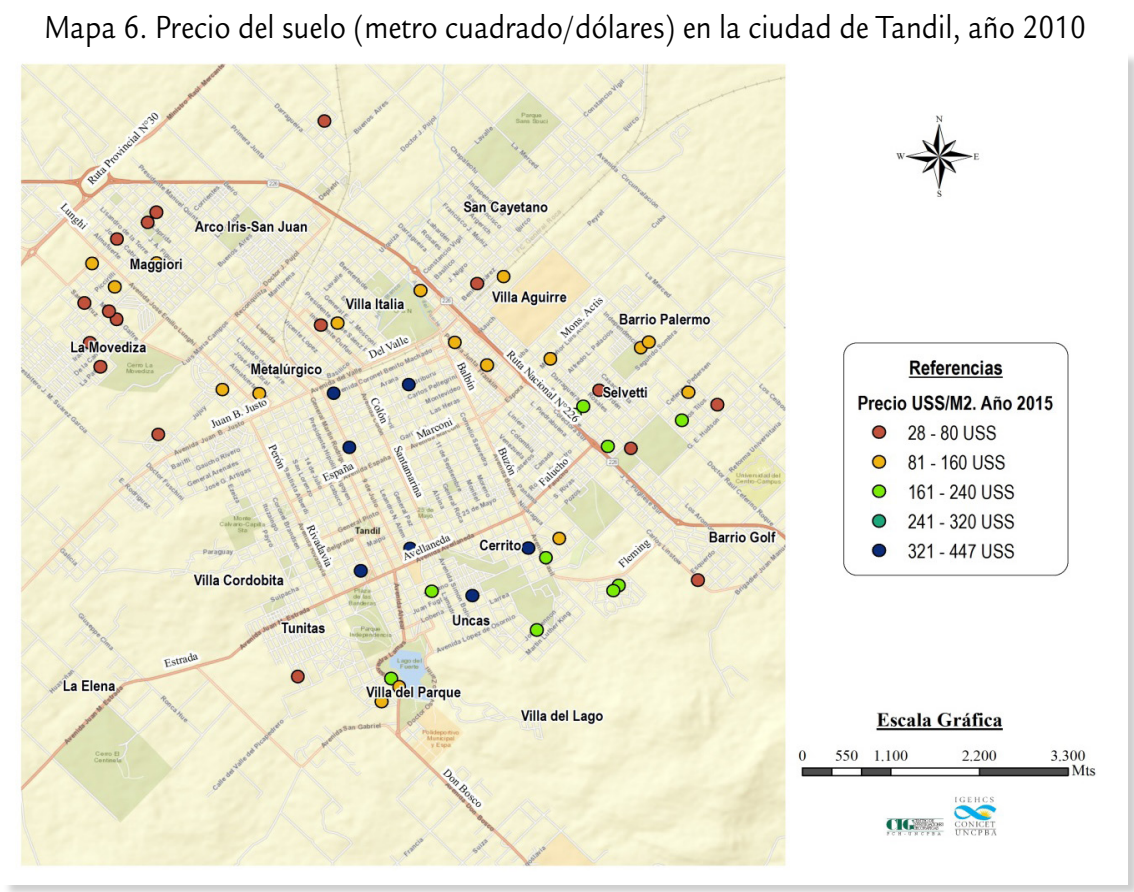

Fuente: elaboración personal con base en ofertas realizadas por las inmobiliarias en el suplemento "Negocios y Servicios" del periódico Nueva Era, año 2015

Al cruzar la información obtenida en los registros de los avisos clasificados y los datos aportados en las entrevistas a los informantes clave, se evidencia que efectivamente a lo largo del período estudiado los precios del suelo urbano en la ciudad de Tandil crecieron muy por encima del incremento que, en ese mismo lapso, registraron los ingresos de la masa trabajadora ${ }^{5}$. Al mismo tiempo, se destaca la consolidación del sector sur y centro del ejido urbano como los espacios más valorizados de la ciudad, pero se observa que las ofertas para los barrios periféricos se incrementaron notablemente, tanto en cantidad como en el valor del metro cuadrado. Este último dato

\footnotetext{
5 Según Herrera (2017) en noviembre del año 2000 el salario mínimo, vital y móvil en la Argentina alcanzaba los U\$S200, mientras que el salario promedio de los empleados registrados ascendía a U\$S803. En noviembre de 2002, luego de la salida de la convertibilidad, estos valores cayeron a U\$S57 y U\$S310, respectivamente, para luego recuperarse y alcanzar en diciembre de 2015 la cifra de U\$S423 el salario mínimo, vital y móvil y U\$S1.436 el salario promedio de los empleados registrados.
}

pone de manifiesto que muchos de estos lugares al norte del ejido urbano, que anteriormente no poseían atractivo inmobiliario, en los últimos quince años comenzaron a constituirse en un eje de expansión para los espacios residenciales de aquellos grupos sociales correspondientes a la masa trabajadora que lograron alcanzar alguna capacidad de ahorro y comenzaron a demandar suelo urbano para la construcción de sus viviendas como bienes de uso.

Asimismo, se decidió contrastar esta información obtenida a partir del relevamiento de clasificados en el periódico local con la percepción de los martilleros y los empresarios de la construcción. Para ello se le consultó a los entrevistados cuáles habían sido los lugares más valorizados por las inversiones inmobiliarias luego de la salida de la convertibilidad. En este sentido, a partir de las respuestas obtenidas se evidenció, como lo muestra el Mapa 7, que el centro y varios lugares del sur de la ciudad reci- 
bieron la mayor cantidad de menciones. Pero, mientras se destaca que en el centro se generó una valorización del suelo en base a la potencialidad que el medio construido ofrece para la generación de edificios en altura, en el sur, proliferaron los proyectos de espacios residenciales con viviendas unifamiliares para sectores de altos ingresos, debido a sus aptitudes pai- sajísticas y a la conformación de un mercado correspondiente a la vivienda privilegiada. Esto se tradujo en diferentes formatos residenciales, como barrios parque, urbanizaciones especiales y barrios cerrados, a los cuales también se le adicionaron los emprendimientos destinados a la actividad turística y recreativa, principalmente, hoteles y cabañas.

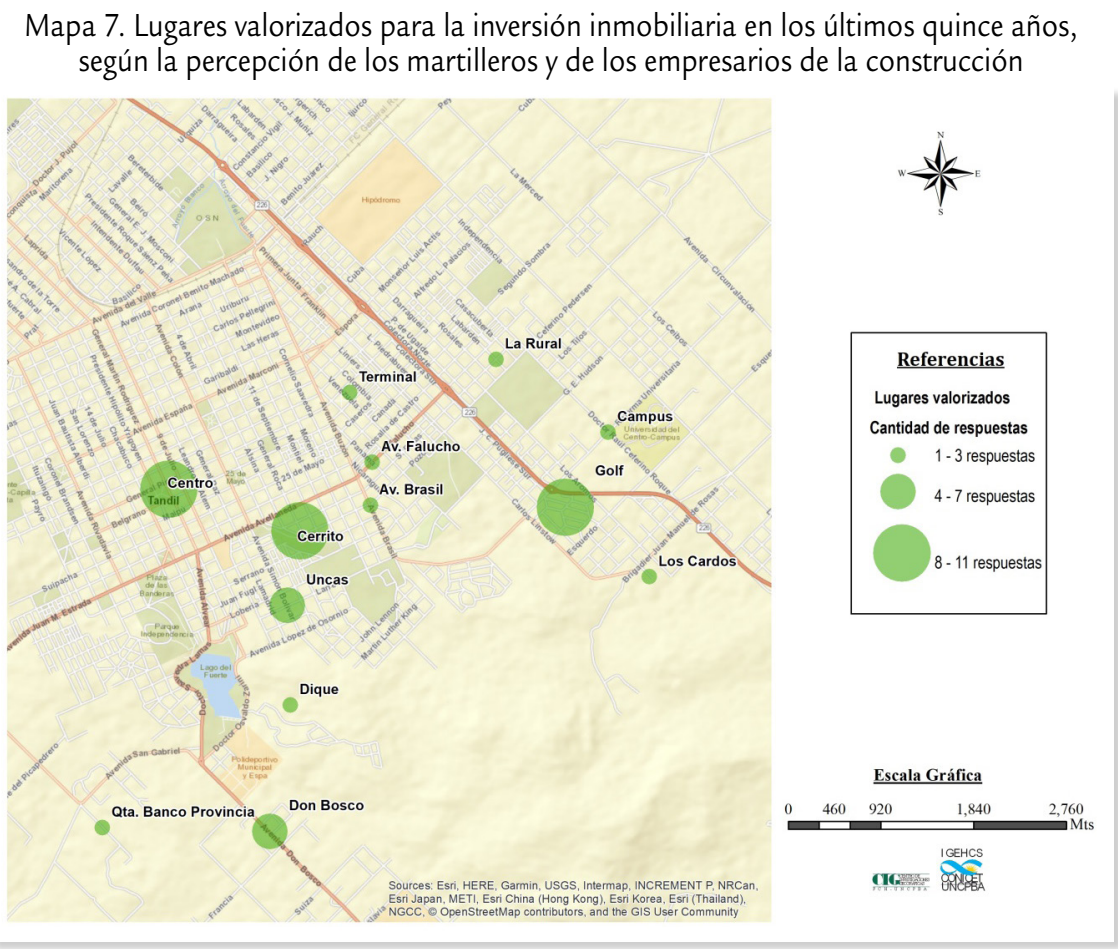

Fuente: elaboración personal con base en las respuestas obtenidas de los informantes clave

A su vez, a raíz de esta pregunta surgieron otros datos interesantes a destacar. En primer lugar, varios entrevistados mencionaron que desde hace aproximadamente cinco años, desde el lanzamiento del programa de créditos hipotecario Pro.Cre.Ar ${ }^{6}$, se valorizó un importante sector hacia el norte de la ciudad, a partir de la conformación de espacios residenciales para grupos sociales incluidos dentro de la masa tra-

6 El Programa de Crédito Argentino del Bicentenario para la Vivienda Única Familiar (PRO.CRE.AR.) fue implementado en el año 2012 mediante el Decreto Ley N912. El mismo incluiría diferentes líneas: 1) Construcción, 2) Ampliación y terminación, 3) Refacción, 4) Compra de terreno y construcción, 5) Compra de viviendas a estrenar y 6) una serie de Desarrollos Urbanísticos realizados en algunas ciudades del país. Los créditos serían entregados por el Banco Hipotecario, con un plazo de pago de entre 20 y 30 años y una tasa de interés de entre el $2 \%$ y el $14 \%$. bajadora, que en los años precedentes registraron cierta mejora en sus condiciones materiales. Concretamente, los barrios mencionados fueron San Juan, Arco Iris y Villa Italia Norte. También se identificó a los barrios de la Estación y del Hospital, pertenecientes al segundo anillo céntrico, como lugares "de reciclado", es decir, barrios tradicionales de la ciudad, con edificaciones antiguas, donde los empresarios inmobiliarios invierten en la compra de esas viejas viviendas, para demolerlas y luego realizar complejos de departamentos.

Además, resulta relevante mencionar que surgieron referencias negativas hacia determinados barrios, a pesar de que en las entrevistas no se indagó sobre ello. Particularmente, cinco infor- 
mantes clave mencionaron a Movediza y a Tunitas, como lugares no aptos para el desarrollo inmobiliario a causa de las características de su población (Mapa 8). Según lo expresado por estas personas, si bien estos espacios también poseen un entorno natural con muchas potencialidades, la precariedad de sus infraestructuras y el estigma social que se ha generado alrededor de ellos, no los hacen atractivos para las inversiones. Estas apreciaciones parecen estar ligadas a la subjetividad de la clase social a la que pertenecen los martilleros y constructores, que no se corresponde de manera fidedigna a la realidad objetiva del mercado inmobiliario, en tanto que el relevamiento de ofertas evidenció un incremento significativo de terrenos en venta para el barrio Movediza, el cual se constituyó en los últimos años en uno de los ejes de expansión residencial más importante para los grupos sociales pertenecientes a la población trabajadora.

En las últimas décadas, Movediza y Tunitas fueron los barrios a los cuales estuvieron destinados, en mayor medida, los programas habitacionales generados desde los organismos públicos. En el caso de Tunitas, se destacan algunas operatorias del FONAVI a comienzos de la década de 1980 y de Pro-Casa entre fines de esa misma década y comienzos de la siguiente. En lo que respecta a Movediza, a partir de la década de 1990 se localizaron allí los programas vinculados a Autoconstrucción y Ayuda Mutua y, en los años 2000, los barrios correspondientes al Plan Federal de Construcción de Viviendas. A su vez, hay que remarcar que, según el Relevamiento Público Provincial de Villas y Asentamientos Precarios realizado en el año 2016, de los siete barrios informales que existen en la ciudad, dos se localizan en Movediza y otro en Tunitas. De esta forma, parte de la morfología de estos lugares corresponde con las características de los conjuntos de vivienda social que se intercalan con algunos espacios informales. Sin embargo, esta situación no ha imposibilitado que en los últimos quince años surjan incentivos para que gran parte de los terrenos de estos barrios se fraccionen y comercialicen para construcción de viviendas unifamiliares. Si bien es cierto que no se registran inversiones destinadas a realizar el tipo de emprendimientos que existen en otros sectores del ejido urbano, sí se observa un importante crecimiento de estos espacios residenciales a partir de la adquisición de terrenos para la construcción de viviendas unifamiliares.

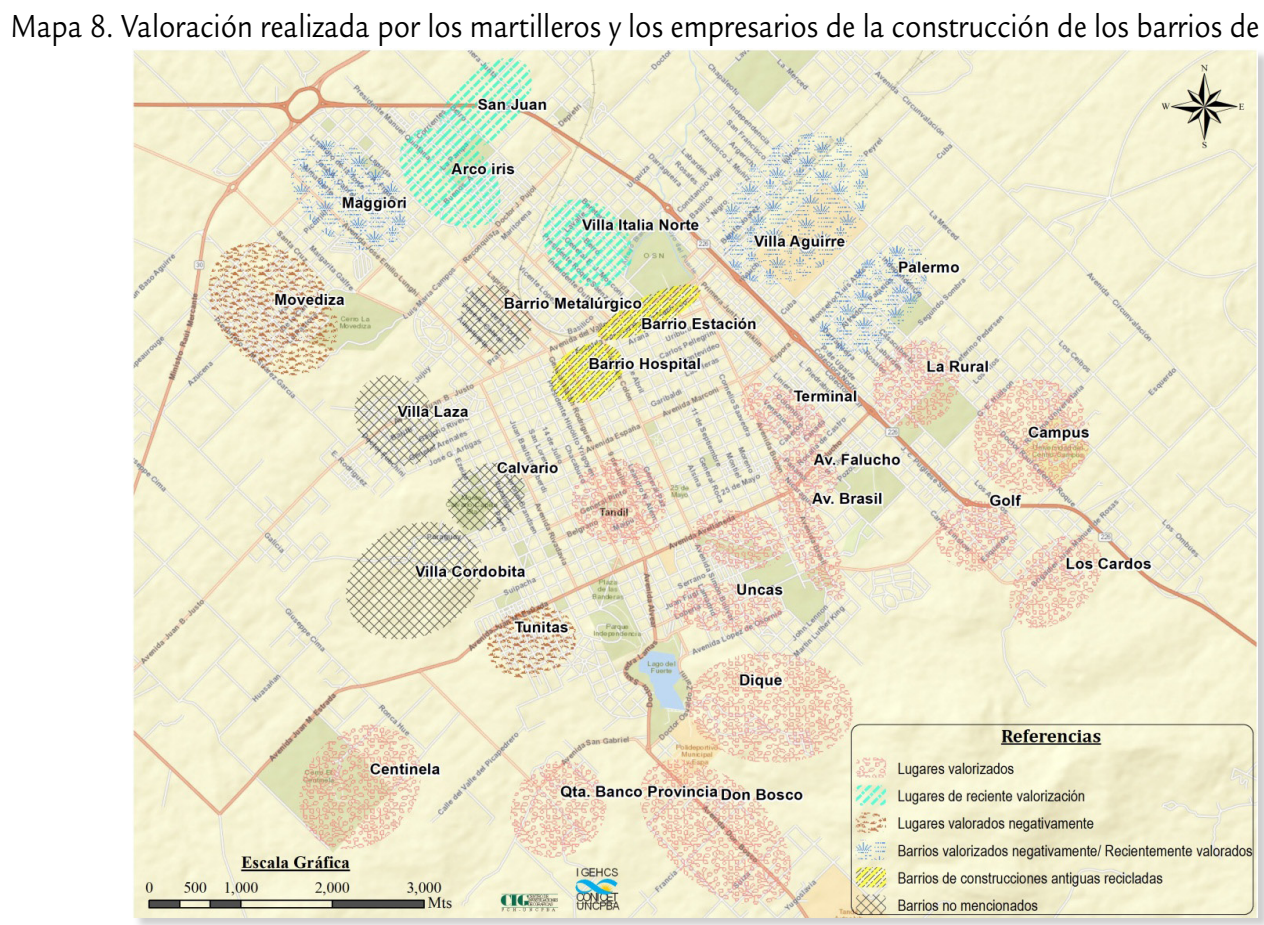

Fuente: elaboración personal con base en las respuestas obtenidas de los informantes clave 
Finalmente, puede identificarse un último grupo de barrios, que en algunas entrevistas fueron señalados como lugares recientemente valorizados, pero que otros martilleros y constructores los identificaron dentro de los lugares estigmatizados y de bajo valor inmobiliario. Este es el caso de Villa Aguirre, Palermo y Maggiori, que se encontrarían en un proceso de transición, donde algunos sectores puntuales, en los últimos años, empezaron a cambiar su fisonomía a raíz de la construcción de diversos proyectos inmobiliarios realizados por constructores locales y que, en buena medida, fueron demandados por beneficiarios del programa de créditos Pro.Cre.Ar. (Mapa 8).

\section{Consideraciones FINALES}

Al igual que en el resto del país, las características que asumió la producción de la vivienda en la ciudad de Tandil durante el período de la postconvertibilidad, agudizó los rasgos de un modelo de urbanización desigual y excluyente. El incremento de las rentas y las ganancias extraordinarias obtenidas por medio de las inversiones inmobiliarias darían lugar a la proliferación de nuevos formatos residenciales, al mismo tiempo que alejarían cada vez más a la masa trabajadora de la posibilidad de acceder a la propiedad de los inmuebles.

Si bien es cierto que, como manifestaron varios informantes clave, a lo largo de estos años la ciudad de Tandil consolidó su importancia como nodo regional en el sureste de la provincia de Buenos Aires y eso le permitió que varias de sus actividades económicas registraran índices de crecimiento por encima de la media del país, puede considerarse que, en realidad, la dinámica que adquirió el sector inmobiliario se explica con mayor claridad si se observan los vaivenes de la economía nacional y las oportunidades o los condicionamientos que ésta ofreció para su desarrollo. En este sentido, se percibe que los martilleros y los empresarios de la construcción entrevistados suelen subestimar los factores macroeconómicos y dimensionar de manera excesiva los factores locales al momento de analizar el proceso por el que atravesó la dinámica inmobiliaria en los últimos años.

A escala intraurbana este nuevo escenario se expresa evidenciando algunas tendencias. En primer lugar, se consolida un mercado de la vivienda privilegiada que se manifiesta en dos subespacios:

1) Viviendas unifamiliares en barrios cerrados, urbanizaciones especiales y barrio-parques en el sur de la ciudad: son producidas incorporando elementos del paisaje serrano con el objetivo de valorizar las inversiones y comercializar productos inmobiliarios asociados a un estilo de vida, donde predomina la tranquilidad y el contacto con la naturaleza. Estos inmuebles son mayoritariamente demandados por migrantes provenientes de las grandes ciudades. De acuerdo al relevamiento de precios realizado en base a los avisos clasificados, los lugares en donde se ubican estos proyectos residenciales alcanzaron los valores por metro cuadrado más elevados de la ciudad durante todo el período, junto con el centro comercial. La concreción de estas iniciativas se realizó mediante capitales locales, que requirieron modificar profundamente el ecosistema serrano. Al mismo tiempo, se evidencia que estos nuevos espacios residenciales provocaron una mayor dispersión y extensión del ejido urbano hacia el sur, abandonando la forma compacta que presentaba hasta finales del siglo XX.

2) Departamentos de alta categoría en edificios construidos en el centro de la ciudad: los capitales que los construyen también son de origen local, siendo dos las empresas constructoras de mayor importancia: Grupo ZYASA y Constructora Bértoli. La incorporación de valor, en este caso, no se da por los elementos del paisaje serrano sino por las amenities. La proliferación de estos inmuebles en el último período evidencia un acelerado proceso de verticalización en la ciudad. Vale remarcar que en estos dos espacios es donde se han registrado mayores presiones por parte de los propietarios del suelo, de los empresarios constructores y de los martilleros para 
que el gobierno municipal flexibilice las normas de urbanización que se implementaron mediante el Plan de Desarrollo Territorial. En este sentido, en el año 2011 el Honorable Concejo Deliberante aprobó la Ordenanza N¹2.679, que habilitó a que se realicen convenios urbanísticos en los cuales era posible establecer excepciones al Plan de Desarrollo Territorial. Hasta la fecha se han realizado treinta convenios urbanísticos, de los cuales una importante proporción implican la modificación de los índices de ocupación y del tamaño de las parcelas que es posible generar sobre el área serrana y el centro de la ciudad. Claramente, en el contexto actual la posibilidad de modificar dichos indicadores son los que posibilitan la generación de rentas extraordinarias que los propietarios del suelo y los inversores intentan captar.

Por su parte, en el centro y en los barrios aledaños a este también se produjo una importante cantidad de complejos de departamentos de segunda categoría, que podrían incluirse dentro del mercado de la vivienda normal (Topalov, 1984). Dichos inmuebles son demandados, en una proporción importante, por tenedores de vivienda inversores para ofrecerlos como bien de uso a estudiantes, hogares recién constituidos y/o de tamaño reducido. Las empresas constructoras son de pequeñas dimensiones y de origen local.

A su vez, pueden identificarse otros espacios residenciales pertenecientes al mercado de la vivienda normal en el eje norte de la ciudad. No obstante, en estos lugares la producción se generó articuladamente con algún tipo de intervención del Estado, ya que gran parte de los constructores entrevistados manifestaron haber trabajado en la edificación de viviendas particulares para clientes que eran, en buena medida, beneficiarios del programa de créditos hipotecarios lanzado por el gobierno nacional (Pro.Cre.Ar.). En este sentido, el perfil de estos barrios no estuvo caracterizado por la construcción de complejos de departamentos como en el centro, sino por las viviendas unifamiliares. Esta situación se corresponde con lo que los informantes clave percibieron como barrios valoriza- dos recientemente. También este dato coincide con lo evidenciado por el relevamiento de avisos clasificados, con respecto al incremento de la oferta de lotes para la venta que se visualizó a lo largo del período en toda la periferia norte, lo cual puede explicarse por la existencia de una demanda generada por grupos sociales pertenecientes a la masa trabajadora, quienes mediante cierta capacidad de ahorro y el acceso a créditos hipotecarios, comenzaron a visualizar estos espacios como posibles lugares de residencia.

Por su parte, el Estado ha realizado una importante inversión en la producción de vivienda social. Mayoritariamente, estos conjuntos habitacionales se ubicaron en el barrio Movediza, valorizado negativamente por los actores del mercado inmobiliario. La concentración de la inversión pública en vivienda en este barrio se debe a que allí se encontraban la mayor cantidad de terrenos fiscales, que fueron adjudicados a las operatorias correspondientes al Plan Federal de Construcción de Viviendas y otras. A su vez, la ciudad de Tandil fue seleccionada para la construcción de uno de los desarrollos urbanísticos que se impulsaron desde el Pro.Cre.Ar. El mismo contempló la edificación de 629 viviendas en el barrio Villa Italia Norte, constituyéndose en el barrio social de mayor envergadura que se haya construido en la ciudad hasta el presente. Dicha obra tuvo un importante efecto de revitalización y valorización de los barrios contiguos, ya que incluyó obras de infraestructura (apertura de calles, pavimentación y extensión de servicios) que permitieron conectar al norte del ejido urbano con el centro de la ciudad.

De igual manera, es necesario remarcar que estos cambios intra-urbanos del mercado inmobiliario estuvieron acompañados por restricciones en el acceso a la vivienda, lo cual se manifestó, por ejemplo, en indicadores como el régimen de tenencia. Aquí se observa un importante proceso de inquilinización en la ciudad, ya que en diecisiete años se duplicó la proporción de hogares inquilinos, de 15,5\% en 2001 a 30\% en 2018 (INDEC, 2001, 2010; El Eco de Tandil, 21/07/2019) y se redujo no- 
tablemente la proporción de hogares propietarios. Estos datos colaboran en reafirmar las dificultades que la masa trabajadora encontró para acceder a la vivienda propia, a causa del desfasaje que se produjo entre el incremento de los valores de los inmuebles y el aumento

\section{REFERENCIAS}

Auguste, S. y Seffino, M. (2013). El boom inmobiliario. Newsletter, 4, 6-9. Recuperado de https://www.econ.unicen.edu.ar/graduados/ images/pdf/04_newsletter.pdf (consulta 5 de agosto de 2019).

Baer, L. (2008). Crecimiento económico, mercado inmobiliario y ausencia de política de suelo: un análisis de la expansión del espacio residencial de la ciudad de Buenos Aires en los 2000. Proyección, 2(5).

Baer, L. (2011). El mercado de suelo formal de la Ciudad de Buenos Aires en su contexto metropolitano. Tesis doctoral. Facultad de Filosofía y Letras. Universidad de Buenos Aires. Buenos Aires, Argentina.

Campos, G.; Castiglioni, L.; Herrera, L. y Valente Ezcurra, D. (2012). El problema de la vivienda y la lucha social. Análisis de casos de ocupación de los barrios ex Smata y la Movediza. En S. Fernández Soto (Org.) Estado, políticas sociales y sociedad. Debates latinoamericanos. Tandil: UNICEN.

Castells, M. (1986). La ciudad y las masas. Sociología de los movimientos sociales urbanos. Madrid: Alianza Universidad Textos.

Catenazzi, A. y Reese, E. (2013). Derecho a la ciudad. La dinámica de crecimiento urbano, el déficit habitacional y las asignaturas pendientes. Voces en el Fénix. Recuperado de https:// www.pagina12.com.ar/especiales/archivo/voces_en_el_fenix/002-fenix.pdf (consulta 5 de agosto de 2019).

Del Río, J.P. (2014). Transformaciones habitacionales en la Región Metropolitana de Buenos Aires. El pasaje del neoliberalismo al neodesarrollismo urbano. Geograficando, 10(2), 1-33. Recuperado de http://sedici.unlp.edu.ar/hand- que registraron los ingresos de dichos sectores. En este sentido, se observa una tendencia del mercado inmobiliario donde se acentuó la producción de la vivienda como bien financiero y se redujo la oferta para aquellos que la consideran un bien de uso.

le/10915/43554 (consulta 5 de agosto de 2019). Dirección Provincial de Estadística, Ministerio de Economía de la Provincia de Buenos Aires (2015). Encuesta a Operadores Inmobiliarios 2015. Recuperado de http://www.estadistica.ec. gba.gov.ar/dpe/images/ECONOMIA/Encuesta_prov_2015.pdf

Dirección Provincial de Estadística, Ministerio de Economía de la Provincia de Buenos Aires (2017). Índice Provincial de la Actividad de la Construcción. Recuperado de http://www.estadistica.ec.gba.gov.ar/dpe/index.php/economia/ construccion/encuesta-de-ventas-de-materiales-de-construccion

El Eco de Tandil (01/07/2018). Ante el estancamiento de la construcción, los arquitectos buscan estrategias para paliar la crisis. Recuperado de https:// www.eleco.com.ar/la-ciudad/ante-el-estancamiento-de-la-construccion-los-arquitectos-buscan-estrategias-para-paliar-la-crisis/

El Eco de Tandil (21/07/2019). En Tandil, cerca del 60 por ciento de los vecinos es dueño de su casa y un 30 por ciento alquila. Recuperado de https:// www.eleco.com.ar/la-ciudad/en-tandil-cercadel-60-por-ciento-de-los-vecinos-es-duenode-su-casa-y-un-30-por-ciento-alquila/

Fernández Equiza, A.M. (2017). El crecimiento de la ciudad de Tandil, actores y conflictos (pp. 235-277). En A.M. Fernández Equiza (Comp.) Debates sobre naturaleza y desarrollo. Análisis a distintas escalas. Tandil: Red de Editoriales de Universidades Nacionales.

Fernández Wagner, R. (2014). Los límites de las políticas neo keynesianas en el desarrollo urbano y vivienda ( $1^{\circ}$ Edición, pp. 29-38). En D. Gargantini (Comp.) Hábitat, acceso al suelo y financiamiento. Experiencias alternativas de produc- 
ción socio-habitacional. Córdoba: Universidad Nacional de Córdoba.

Harvey, D. (2012). Ciudades rebeldes. Del derecho de la ciudad a la revolución urbana. Madrid: Akal.

Herrera, H. (2017). El salario en dólares en la Argentina: una evolución y una mirada sobre Latinoamérica. Recuperado de http://eppa.com.ar/ el-salario-en-dolares-en-la-argentina-una-evolucion-y-una-mirada-sobre-latinoamerica/ (consulta 5 de agosto de 2019).

Honorable Concejo Deliberante del Municipio de Tandil (29/12/2011). Ordenanza $N^{\circ}$ 12.679: Proyectos y Convenios Urbanísticos. Recuperado de http://www.hcdtandil.gob.ar/legislacion/ Ordenanza-12679.html

Instituto Nacional de Estadísticas y Censos (INDEC) (2001). Censo Nacional de Población, Hogares y Viviendas 2001. Recuperado de https:// redatam.indec.gob.ar/argbin/RpWebEngine. exe/PortalAction?\&MODE=MAIN\&BASE=CPV2001ARG\&MAIN=WebServerMain.inl

Instituto Nacional de Estadísticas y Censos (INDEC) (2010). Censo Nacional de Población, Hogares y Viviendas 2010. Recuperado de https:// redatam.indec.gob.ar/argbin/RpWebEngine. exe/PortalAction?\&MODE=MAIN\&BASE=CPV2010B\&MAIN=WebServerMain.inl

Iñigo Carrera, N.; Podestá, J. y Fernández, F. (1996). Situación de los grupos sociales fundamentales en la Argentina. La situación del proletariado. Razón y Revolución, 2.

Jaramillo, S. (2009). Hacia una teoría de la renta del suelo urbana. Bogotá: Universidad de los Andes. Lan, D. (2011). Territorio, industria, trabajo: división territorial del trabajo y espacio producido en la industria de la ciudad de Tandil. Tesis doctoral, Facultad de Humanidades y Ciencias de la Educación, Universidad de La Plata. Recuperado de http://www.memoria.fahce.unlp.edu.ar/ library? $\mathrm{a}=\mathrm{d} \& \mathrm{c}=$ tesis $\& \mathrm{~d}=\mathrm{J}$ te 430

Lan, D.; Linares, S.; Di Nucci, J. y López Pons, M.M. (2010). La lógica de la organización espacial en la ciudad de Tandil ( $1^{\circ}$ Edición, pp. 29-155). En D. Elias et. al. (Org.) Agentes econômicos e reestruturação urbana e regional: Uberlândia e Tandil. São Paulo: Editora Expressão Popular.

Lefebvre, H. (1969). El derecho a la ciudad. Barcelona: Ediciones Península.

Morales Schechinger, C. (2005). Algunas peculiaridades del mercado de suelo urbano. Material bibliográfico ofrecido para el curso virtual "Mercado de suelo urbano en América Latina”. Lincoln Institute of Land Policy.

Municipio de Tandil (2005). Plan de Desarrollo Territorial Tandil. Recuperado de https://www. argentina.gob.ar/interior/secretaria-de-planificacion-territorial-y-coordinacion-de-obra-publica/planes-locales/buenosaires

Reese, E. (2006). La situación actual de la gestión urbana y la agenda de las ciudades en la Argentina. Medio ambiente y urbanización, 6, 3-22.

Registro Público Provincial de Villas y Asentamientos Precarios (2016). Subsecretaría Social de Tierras, Urbanismo y Vivienda del Ministerio de Infraestructura y Servicios Públicos de la Provincia de Buenos Aires. Recuperado de: http://190.188.234.6/mapa/

Segura, R. (2014). El espacio urbano y la (re)producción de desigualdades sociales. Desacoples entre distribución del ingreso y patrones de urbanización en ciudades latinoamericanas. Working Paper Series, (65), 1 - 31.

Topalov, C. (1984). Ganancias y rentas urbanas. Elementos teóricos. Madrid: Siglo XXI Editores de España S. A.

\footnotetext{
Alejandro Migueltorena es Doctor en Geografía y Becario Posdoctoral en Temas Estratégicos, CONICET. Actualmente es Jefe de Trabajos Prácticos en el Departamento Epistemológico-Metodológico de la Facultad de Ciencias Humanas de la UNCPBA. Sus temas de investigación son: producción del espacio urbano, mercado inmobiliario, políticas habitacionales y acceso al hábitat en la ciudad de Tandil. Centro de Investigaciones Geográficas e Instituto de Geografía, Historia y Ciencias Sociales CIG/IGEHCS (UNCPBA/CONICET). Pinto 399, (7000) Tandil, Buenos Aires, Argentina, ale_gardey@hotmail.com
} 